Referencia para citar este artículo: Molina-Chávez, W. M. \& Álvarez-Valdés, C. (2017). Imaginarios sociales sobre lo juvenil en el Chile contemporáneo. Revista Latinoamericana de Ciencias Sociales, Niñez y Juventud, 15(1), pp. 85-100.

\title{
Imaginarios sociales sobre lo juvenil en el Chile contemporáneo*
}

\author{
WALter Manuel Molina-CháVEZ ${ }^{*}$ \\ Profesor Universidad de Magallanes, Chile. \\ CAROLINA ÁLVAREZ-VALDÉS $S^{* * *}$ \\ Investigadora Universidad de Chile, Chile.
}

\begin{abstract}
Artículo recibido en marzo 7 de 2016; artículo aceptado en mayo 17 de 2016 (Eds.)
\end{abstract}
- Resumen (analítico): en este artículo, se presentan los resultados de una investigación cuyo objetivo fue identificar imaginarios sociales emergentes sobre lo juvenil en el Chile contemporáneo. Es un estudio cualitativo basado en el análisis de trece grupos de discusión realizados en cinco regiones del país. La selección de los participantes en el estudio consideró a estudiantes que cursan su último año de educación secundaria en Chile. Entre los resultados más relevantes se encuentra la identificación de un imaginario social sobre lo juvenil como un desafío de escolarización, que se estructura conflictivamente con énfasis en varias dimensiones y procesos claves en la configuración de la condición social de las juventudes chilenas contemporáneas.

Palabras Claves: Imaginarios sociales, juventudes, desarrollo humano, escolarización (Tesauro de Ciencias Sociales de la Unesco).

\section{Social imaginaries of youth in contemporary Chile}

- Abstract (analytical): This paper presents the finding/results of an investigation that had the objective of identifying emerging social imaginaries related to youth in contemporary Chile. This is a qualitative study based on the analysis of thirteen discussion groups, conducted in five regions across the country. Participants in the study were studying their last year of secondary education/ high school in Chile. Among the most relevant results is the identification of a social imaginary of youth as a permanent challenge to be controlled by the education system, which is structured as a conflict into the foundation of emphasizing different dimensions and processes that are considered essential in the configuration of the social condition of contemporary Chilean youth.

Key words: Social Imaginaries, youths, human development, schooling (Social Sciences Unesco Thesaurus).

\footnotetext{
* El presente artículo de reflexión se sustenta en la investigación realizada por los autores en el marco del Proyecto Anillo "Juventudes: Transformaciones socioeconómicas, sociopolíticas y socioculturales de las y los jóvenes en el Chile contemporáneo" (SOC 1108) financiado por Conicyt-Chile, cuyo inicio fue el 5 de diciembre de 2012 y su finalización el 5 de mayo de 2016. La reflexión aquí presentada corresponde al trabajo realizado durante el año 2014. El Área de conocimiento del presente artículo pertenece a la Sociología, mientras que la sub área corresponde a los estudios de Juventudes.

** Doctor en Ciencias de la Educación, por la Pontificia Universidad Católica de Chile. Profesor Universidad de Magallanes, Departamento de Ciencias Sociales, Carrera de Trabajo Social, Casilla 113-D, Punta Arenas, Chile. Correo electrónico: walter.molina@umag.cl

*** Magíster en Ciencias Sociales, mención Sociología de la Modernización, Universidad de Chile. Investigadora Asistente Proyecto Anillo Juventudes. Integrante Núcleo de Investigación y Acción en Juventudes, Universidad de Chile. Correo electrónico: caroalvarezvaldes@gmail.com
} 


\section{Imaginários sociais sobre o juvenil no Chile contemporâneo}

- Resumo (analítico): Neste artigo apresentam-se os resultados de uma pesquisa cujo objetivo foi identificar imaginários sociais emergentes sobre o juvenil no Chile contemporâneo. É um estudo qualitativo baseado na análise de treze grupos de discussão realizados em cinco regiões do país. A seleção dos participantes no estudo considerou a estudantes que cursam seu último ano de educação secundária em Chile. Entre os resultados mais relevantes se encontram a identificação de um imaginário social sobre o juvenil como um desafio permanente de escolarização, o qual se estrutura conflituosamente sobre a base de enfatizar diversas dimensões e processos chaves na configuração da condição social das juventudes chilenas contemporâneas.

Palavras chave: Imaginários sociais, juventudes, desenvolvimento humano, escolarização (Thesaurus de Ciências Sociais da Unesco).

-1. Introducción. -2. Metodología. -3. Lo juvenil como imaginario social en construcción en el Chile contemporáneo. -4. Resultados. -5. Conclusiones. -Lista de referencias.

\section{"Juventud, divino tesoro, ¡Ya te vas para no volver!” Rubén Darío}

\section{Introducción}

Los imaginarios sociales sobre lo juvenil están referidos a la institución de un conjunto de creencias, normas, valores, modos de vida y prácticas sociales que estructuran una cierta noción sobre las juventudes en el Chile actual. Al respecto, Castoriadis (2007) señala lo siguiente: "la institución de la sociedad es en cada momento institución de un magma de significaciones imaginarias sociales, que podemos y debemos llamar mundo de significaciones" (2007, p. 556). Desde esta perspectiva de análisis, se autoriza a rastrear preliminarmente un conjunto de ejes de significación emergentes en el contexto actual en torno a la idea de ser joven desde la propia experiencia sociológica y en los discursos de las y los jóvenes chilenos actuales.

Se puede sostener que a comienzos del siglo XX emergen por primera vez las juventudes latinoamericanas como un sujeto social y político, que situadas en el seno de la conflictiva estructura social e impulsadas por un imaginario social de rebeldía y cambio recorrerán prácticamente todos los escenarios de lucha social y política. Lo anterior, permite sostener como lo hacen algunos autores claves de la filosofía latinoamericana del sujeto (Zemelman, 1998, Hinkelammert, 2003, Acosta,
2011) que dicha emergencia de las juventudes en América Latina expresa la presencia de un sujeto histórico concreto que en la interfaz del siglo XX y XXI logra desplegarse y visibilizar su presencia en su dimensión individual $\mathrm{y}$ colectiva.

En este contexto analítico, lo propiamente juvenil es un proceso de construcción social compleja que, junto con estar articulado en torno a un eje temporal biográfico agenciado por los propios sujetos juveniles, implica simultáneamente la construcción de un imaginario social de dicha temporalidad biográfica, de sus vivencias más relevantes, de sus principales desafíos existenciales e instituye social e imaginariamente una determinada resolución al enigma de lo juvenil como experiencia sociológica clave en la emergencia de las sociedades capitalistas y su proyecto de modernidad propio.

Por ello, es de interés en la presente investigación identificar algunos elementos simbólicos (signos) del imaginario social sobre juventud que comienza a configurarse en Chile a partir de un contexto de profundas transformaciones en el ámbito económico, social, político y cultural en las últimas cuatro décadas. Esto es consistente con las hipótesis que han formulado algunos autores (Duarte, 2015) que sostienen que las juventudes chilenas contemporáneas conforman una metáfora de dichas transformaciones, es decir, lo que les sucede a las y los jóvenes chilenos es simultáneamente lo que le ocurre a la sociedad chilena en su conjunto y viceversa. 


\section{Metodología}

El corpus de datos que se analizarán proviene de 13 grupos de discusión realizados con jóvenes estudiantes que cursan el último año de educación secundaria en varias regiones de Chile. La muestra estructurada para este estudio es no probabilística y siguió los procedimientos de muestreo estructural (Canales, 1994) para la elección de los liceos y de los estudiantes que participaron en los grupos de discusión. Esta selección consideró varias realidades sociales, por ello, se trabajó con establecimientos educacionales que dieran cuenta de diversos sectores de la sociedad chilena. Cabe señalar que los establecimientos de educación secundaria en Chile se diferencian entre los que acceden a financiamiento $\mathrm{o}$ subvención pública (liceos municipales o liceos particulares subvencionados por el Estado) y los que sólo cuentan con financiamiento privado de las familias. En este caso, se trata de particulares pagados que también están incluidos en este muestreo. En este sentido, el tipo de financiamiento y el monto que debían financiar las familias fue un factor que determinó la muestra, pues indica sus condiciones económicas, sociales y culturales. Por otra parte, la composición interna de los grupos de discusión se determinó por medio de la selección de jóvenes que cursaban el último año de secundaria, pues, este momento de pasajes a la educación terciaria (universidades, centros de formación técnico, institutos profesionales) los sitúa en una posición reflexiva sobre sí mismos, su juventud, la sociedad en la que viven y los pasos que deben o quieren seguir.

Estas escuelas o liceos están localizadas en cinco regiones de Chile. El detalle de la distribución se observa en el siguiente cuadro:

\begin{tabular}{|l|l|l|l|}
\hline \multicolumn{1}{|c|}{ Liceo } & \multicolumn{1}{c|}{ Región } & \multicolumn{1}{c|}{$\begin{array}{c}\text { Dependencia } \\
\text { administrativa }\end{array}$} \\
\hline Liceo 1 & Metropolitana & Santiago & Municipal \\
\hline Liceo 2 & Metropolitana & Santiago & Particular Subvencionado \\
\hline Liceo 3 & Metropolitana & Santiago & Particular subvencionado \\
\hline Liceo 4 & Metropolitana & Macul & Municipal \\
\hline Liceo 5 & Metropolitana & Las Condes & Particular Pagado \\
\hline Liceo 6 & Metropolitana & Nuñoa & Particular subvencionado \\
\hline Liceo 7 & Quinta Región & Valparaíso & Municipal \\
\hline Liceo 8 & Sexta Región & San Fernando & Particular Subvencionado \\
\hline Liceo 9 & Séptima Región & Curicó & Particular subvencionado \\
\hline Liceo 10 & Séptima Región & Talca & Particular subvencionado \\
\hline Liceo 11 & Octava Región & Talcahuano & Municipal \\
\hline Liceo 12 & Octava Región & Concepción & Municipal \\
\hline Liceo 13 & $\begin{array}{l}\text { Décima Segunda } \\
\text { Región }\end{array}$ & Punta Arenas & Particular subvencionado \\
\hline
\end{tabular}

Para enmarcar el análisis de los datos, en un primer momento se revisaron algunos estudios considerados clásicos en la sociología de la juventud. Esto se hizo, con el fin de explorar conceptos y procesos considerados clásicos en torno a la definición de lo juvenil en la actualidad. Por otra parte, el análisis se orientó por la hipótesis de trabajo que sostiene que en la actualidad se estarían redefiniendo las trayectorias sociales y ciertos hitos juveniles asociadas al tiempo biográfico
(Canales, Ghiardo \& Opazo, 2015, p. 52) o el tiempo de la individuación de las y los jóvenes escolarizados en el Chile contemporáneo. En este sentido, el egreso de la enseñanza secundaria se convertiría en un hito relevante en el camino de preparación para el "mundo adulto" y especialmente en relación a dos procesos biográficos considerados claves: a) formación de expectativas en torno asumir responsabilidades para el futuro, b) procesos de subjetivación o distanciamiento crítico en torno 
a la autoridad, disciplina, obediencia e (in) subordinación a los mandatos adultos.

A partir de estas orientaciones teóricas y metodológicas de la investigación, se procedió revisar parte del material de campo, en pos de identificar, a modo de hipótesis, algunos ejes de significación que estén a la base de la institución de imaginarios sociales sobre "lo juvenil" y que a su vez pudieran estar eventualmente conectados, ya sea con algunas de las "ideas clásicas" sobre juventud o alternativamente con aspectos discursivos emergentes de las y los jóvenes chilenos.

\section{Lo juvenil como imaginario social en construcción en el Chile contemporáneo}

Desde un punto de vista socio-histórico más amplio, González y Feixa (2013) plantean que la presencia y visibilidad social de los jóvenes y lo juvenil en las sociedades latinoamericanas se ha movido pendularmente desde un primer momento de total invisibilidad social verificada desde mediados del Siglo XIX. Transitando, posteriormente, por periodos de incipiente visibilidad socio-cultural en el contexto de la expansión de las instituciones educativas en la mayor parte de los países latinoamericanos, especialmente en el caso chileno y argentino. Un momento de gran visibilidad social sería la estructuración del movimiento de reforma universitaria desplegado en la ciudad argentina de Córdova en el año 1918, lo cual dio un gran impulso y dinamismo a la construcción socioimaginaria de las juventudes latinoamericanas. Al respecto, los autores citados sostienen lo siguiente:

"Así y en forma progresiva, las juventudes latinoamericanas se irán asentando al amparo de los espacios que las mismas conformaciones sociales de la región irán construyendo, posibilitados por la expansión educativa y la ampliación de las capas medias urbanas. Todo ello en el contexto de la modernización y las políticas desarrollistas operantes en América Latina, donde los jóvenes comienzan a ser definidos como sujetos de derecho y sujetos de consumo aceleradamente en las décadas del 50 y 60. De este modo se comprende un transcurso que va desde los que la disfrutan hasta los que padecen la juventud" (González \& Feixa, 2013, p. 13).

Deestemodo, se puede se puede sostenerque a comienzos del Siglo XX emergen por primera vez las juventudes latinoamericanas como un sujeto social y político que situadas en el seno de la conflictiva estructura social e impulsadas por un imaginario social de rebeldía y cambio recorrerán prácticamente todos los escenarios de lucha social y política de este convulsionado Siglo XX. Sin embargo, desde nuestro propio punto de vista en la interfaz del Siglo XX y XXI comienzan a emerger otros imaginarios sociales sobre lo juvenil que comienzan a destacar más la dimensión individual por sobre los aspectos colectivos de la experiencia juvenil contemporánea. Uno de los hitos más relevantes en este proceso de progresiva visibilización social de las y los jóvenes es el surgimiento y estructuración de los sistemas educativos en Latinoamérica y a partir de lo cual se comienza a instituir un imaginario social hegemónico sobre lo juvenil y sus significados sociales dominantes asociados con los desafíos de su formación, preparación y tránsito hacia el mundo de los roles sociales adultos. Con ello, los procesos de escolarización obligatoria comienzan a constituirse cada vez más en una de las características sociológicas centrales de nuestras sociedades latinoamericanas y ello a su vez, contribuye a la configurar identidades y valores que posteriormente serán procesados como elementos o ejes estructurantes de lo juvenil. Más recientemente, la entrada en la escena social de las industrias culturales, la estructuración de mercados orientados al consumo juvenil, junto a la inédita irrupción y expansión de las tecnologías de la información y la comunicación en la vida cotidiana de las y los jóvenes; están marcando las notas definitorias en la configuración imaginaria social de la condición social juvenil en las sociedades capitalistas contemporáneas.

En consideración de lo anterior se sostiene que los imaginarios sociales que se configuran alrededor de un magma de significaciones sobre lo juvenil hacen parte de un largo proceso de construcción socio-imaginaria y simbólico que se despliega a partir de estructuras sociales concretas e históricamente situadas. Cabe señalar, que desde una perspectiva 
teórica reciente, dichos imaginarios han sido caracterizados como "esquemas construidos socialmente que orientan nuestra percepción permiten nuestra explicación hacen posible nuestra intervención en lo que en diferentes sistemas sociales sea tenido como realidad" (Pintos, 2014, p. 7). Su principal potencialidad heurística de dichos imaginarios radicaría en su capacidad para develar determinadas zonas opacas de la sociedad, lo cual permite hacer visible la invisibilidad social. Es decir, se comienzan a hacer visibles los criterios, los significados y mecanismos a través de los cuales determinados grupos poblacionales son considerados socialmente jóvenes en una época determinada y quienes no lo son. Lo anterior, en virtud de sus posiciones en la estructura social, de condicionantes históricas y vivencias biográficas particulares. Estas concepciones sociales y culturales sobre la edad (juvenil, la infancia y otras) se elaboran conflictivamente en el seno de una sociedad y constituyen un determinado campo de poder y conflicto sociopolítico emergente.

En este contexto, y como una forma de abordar la dimensión de complejidad de los imaginarios sociales, Baeza (2003) propone un esquema de análisis, que se refleja en la siguiente figura:

Figura 1: Esquema para la indagación de los imaginarios sociales.

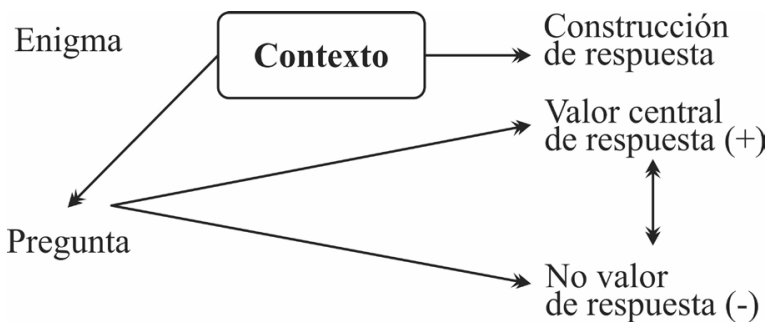

Fuente: Baeza, 2003, p. 54.

Al comenzar a indagar un imaginario específico se parte de una pregunta en torno a algún aspecto de la realidad social indagada. Como consecuencia de esta pregunta o enigma de base se activa un proceso de construción o elaboración social de una respuesta consistente y duradera. Dicha respuesta puede apelar a un principio moral, a un valor o a cualquier elemento simbólico o social que se constituya en el eje articulador del imaginario instituido socialmente. Sinergicamente, todo el proceso de construcción arranca de unos elementos contextuales de los cuales el imaginario se nutre permanentemente. De este modo, la figura muestra todo el dinamismo y la diversidad de materiales socio-imaginarios que se activan en el proceso de configuración de los imaginarios sociales en las sociedades contemporáneas.

Para el caso latinoamericano, Hurtado (2004, p. 113) identifica los siguientes paradigmas sobre la noción de juventud: a) como etapa de transición b) como periodo de crisis c) como actores estratégicos para el desarrollo y d) como construcción cultural. El primero de los imaginarios presentados, se articula en torno a la noción de edad, de adolescencia, cuerpo, ciclo vital, entre otras nociones con un fuerte sesgo o acento en los procesos de maduración biológica. Contextualmente dicho imaginario se conecta con los procesos de extensión progresiva de la edad juvenil que se observa en Chile a comienzos del siglo XX. La segunda construcción imaginaria de lo juvenil gira alrededor de una imagen de las y los jóvenes como un grupo en riesgo o afectados por problemas psicosociales; los que se vincularían preferentemente con los procesos de cambios psicológicos y biológicos propios del tránsito de la adolescencia a la juventud que implicarían riesgos, crisis, descubrimiento e hitos biográficos que marcan el inicio de la sexualidad, el descubrimiento de sus intereses políticos y sus vocaciones profesionales y/o laborales, entre otros aspectos. En tercer lugar, se ubican aquellos imaginarios sociales que tematizan la edad juvenil a partir del protagonismo potencial o efectivo que adquieren las y los jóvenes en relación a los procesos de democratización de nuestras sociedades en distintos momentos de su historia. Y finalmente, Hurtado (2004, p. 114) sostiene que desde una perspectiva antropológica, la juventud emerge como una construcción cultural. Y al respecto el autor precitado puntualiza el siguiente:

Lo juvenil ha sido cargado de contenidos particulares acorde a los contextos donde se construye este imaginario, por tal razón el concepto ha estado vinculado a lo heroico, a la fuerza, al coraje, a 
la vitalidad; desde esta perspectiva la juventud es heroizada e idealizada (Hurtado, 2004, p. 114).

Por otra parte, Alpízar y Bernal (2003) identifican dos imaginarios sociales dominantes, que aunque contradictorios entre sí, permiten caracterizar algunas de las ideas sobre lo juvenil que circulan en la sociedad chilena de fines del siglo XX. Uno de ellos se refiere a cierta concepción de las y los jóvenes como agentes de cambio y el otro imaginario que caracteriza a los jóvenes como problema u obstáculos para el desarrollo. Cómo se puede observar, en la primera perspectiva, se idealiza la condición juvenil y se les otorga a los jóvenes la categoría de agentes de cambio, de esperanza de cambio de la realidad social chilena. En la segunda perspectiva al sujeto juvenil se le asume como problema social; debido principalmente a que se trata de un segmento de la población que enfrenta profundo problemas estructurales y de inserción social.

\subsection{Configuraciones de lo juvenil desde un diálogo intertextual con los estudios clásicos}

En esta sección se revisan algunas hipótesis clásicas y contemporáneas en torno a la noción de juventud, luego se discute su resonancia o visibilidad en las actuales conversaciones sociales en torno la configuración de la condición juvenil en Chile. De este modo, se intenta establecer un diálogo intertextual con los autores considerados clásicos en los estudios de juventud.

Profundizando en este dialogo, y considerando que el interés principal del presente artículo es develar la institución de imaginario social de lo juvenil en el Chile actual; se sostiene preliminarmente que dichos elementos simbólicos y sociales se conectan, directa o indirectamente, con algunas nociones y procesos claves de la condición social juvenil que han sido identificados y analizados por distintos autores considerados clásicos en el campo de los estudios de juventud (Benedict, 2008, Mattelart \& Mattelart, 1970). Uno de los estudios sobre juventud considerados clásicos hasta la actualidad en Chile, es el texto Juventud chilena: Rebeldía y conformismo (Mattelart \& Mattelart, 1970) desarrollada por sociólogos franceses a comienzos de los años setenta y que tuvo amplias repercusiones en la sociedad chilena de la época; pues en alguna medida sus resultados cuestionaron el imaginario social dominante sobre la juventud y que se sintetizaban en algunas de las figuras simbólicas siguientes: juventud politizada, juventud con alto compromiso político, juventud revolucionaria o la juventud como proceso toma de conciencia sobre la necesidad de impulsar cambios sociales profundos, entre otras figuras de la rebeldía juvenil utilizadas. Por el contario, a pesar de lo señalaba el título de la obra, los resultados de dicha investigación mostraban que lo que caracterizaba a las y los jóvenes de la época, eran más bien unas expresiones minoritarias de rebeldía juvenil, la cual canalizadas principalmente a través de organizaciones políticas y sociales en las que participaban de modo intermitente e inestable. Y por otra parte, la investigación daba cuenta de la emergencia de un conformismo incipiente en la mayoría de los hombres y mujeres jóvenes encuestadas en el marco de dicho estudio. Lo anterior expresa claramente como la institución imaginaria social de la juventud en cada época se nutre de diversos materiales, procesos y elementos simbólicos que funcionan como un "magma de significaciones" (Castoriadis, 2007, p. 556) y que están a la base de la configuración imaginaria de lo social y lo juvenil en una época histórica determinada.

Un segundo trabajo clásico es el caso de Benedict (2008), que define la noción juventud como un proceso de transición desde la infancia a la adultez. A pesar de que se trata de una perspectiva antropológica influida fuertemente por el relativismo cultural dominante en los paradigmas antropológicos de la época; consigue aportar elementos analíticos claves tanto para re-pensar el significado de las edades en distintas culturas como para identificar ciertos procesos sociales claves que configurarían la "edad juvenil" y sus principales desafíos en términos de socialización, autonomía y continuidad cultural de las sociedades 
conocidas. Al respecto, Benedict (2008 [1938]) afirma lo siguiente:

"Todas las culturas tienen que lidiar en algún sentido con el ciclo de desarrollo que implica el paso de la infancia a la adultez [...] Cada ser humano que cuenta con todas sus potencialidades, debió ser primero un hijo para ser después un padre; ambos papeles tienen psicológicamente un enorme contraste, pues al inicio tuvo que ser dependiente de otros para conformar su propia existencia y posteriormente él debe otorgar dicha seguridad a otros. Esta discontinuidad en el ciclo de la vida, es un hecho de la naturaleza y es un hecho insoslayable. Aunque es un hecho original que el que el niño se vuelve hombre, la manera en que la transición se efectúa varía de una sociedad a otra, y ninguno de estos puentes culturales específicos debe verse como un camino "natural" hacia la madurez" (Benedict, 2008, pp. 35-36).

Pérez-Islas, Valdez-González y Suárez (2008) destacan que uno de los aportes más significativos de Benedict a los estudios de juventud, consiste en que elabora una propuesta conceptual más amplia sobre la edad, explicitando que entre la naturaleza y el comportamiento humano, hay una serie de mediaciones influenciadas por la cultura, en las cuales surgen contrastes y diferenciaciones específicas que ayudan a conformar los papeles sociales de los individuos en sociedades concretas. En el caso de la relación intergeneracional entre jóvenes y adultos, las oposiciones más importantes, desde su punto de vista, son las siguientes: responsabilidad-no responsabilidad; la relación dominio-sumisión; y el papel sexual contrastado en los diferentes escenarios culturales.

En la actualidad los significados sociales asociados al término transición como algo inmanente a la condición juvenil, constituyen aproximaciones teóricas ampliamente debatidas; específicamente por su énfasis excesivo en destacar el recorrido unidireccional y rígido (no reversible) desde la niñez hacia la adultez. Lo anterior, sin documentar mayormente las diferencias en diversos contextos sociales y culturales de la época en el cual se centran los análisis referidos anteriormente. Desde una posición teórica crítica, Dávila (2015) destaca la emergencia de diversas estructuras de transición que cuestionan ese sesgo lineal, a-histórico y rígido que le han dado algunos de los autores clásicos a los procesos transicionales que van encaminados desde la niñez tardía, la juventud incipiente y la adultez social.

Por otra parte, en los abordajes contemporáneos que estructuran una noción de juventud, siguen muy presentes los enfoques clásicos sobre la juventud como un proceso de transición desde etapas de menor autonomía respecto de la vida adulta. Sin embargo, el autor mencionado (Dávila, 2015) destaca la diversidad de conceptos o expresiones para dar cuenta de la variabilidad social y cultural de dichos procesos transicionales. Un ejemplo de ello, son los conceptos de trayectorias sociales, trayectorias juveniles o cursos de vida, entre otros conceptos, los cuales desde nuestra perspectiva contribuyen a caracterizar más integralmente la condición social juvenil contemporánea.

A partir de los diversos elementos teóricos anteriormente analizados, y provenientes desde enfoques clásicos, re-interpretados a partir de un diálogo abierto con textos e investigaciones contemporáneas sobre juventud(es) en Chile; se han logrado identificar algunos elementos $\mathrm{y}$ procesos que han sido considerados aspectos centrales o estructurantes de la definición y conceptualización de lo juvenil desde dichos enfoques. Algunos de estos elementos son los siguientes: a) Juventud, niñez o adultez como edades y/o cohortes cronológicos en la vida de los seres humanos con significados sociales específicos en las distintas culturas b) El paso de la infancia a la adultez implica ciclos de desarrollo que tienen una fuerte connotación biológica a tal punto que son considerados hechos de la naturaleza mediados por las diversas culturas conocidas c) La transición de la juventud a la adultez tendría una estructuras relativamente rígida, fuerte y que conduce inevitablemente a la adultez como finalidad social normativizada. Desde nuestra propia perspectiva de análisis los tres aspectos precitados constituyen los aspectos centrales de las tematizaciones clásicas de lo juvenil, de 
sus fronteras etarias, de los desafíos sociales implicados en un ciclo de vida o desarrollo concebido desde una miradas con una fuerte raigambre biológica, psicológica y social dominante en la década de los treinta del siglo pasado (Benedict, 2008).

\section{Resultados}

A continuación se presentan algunos resultados preliminares obtenidos a partir del análisis de algunas preguntas claves de la presente investigación y se relacionan directamente con la descripción de la experiencia escolar y social de las y los jóvenes chilenos sobre el momento de su egreso de un ciclo de estudios secundarios, es decir, la culminación formal de su enseñanza secundaria. Por ello, resulta de interés conocer su tematización sobre dicho hito relevante de su propio tiempo biográfico, sus expectativas o proyecciones al terminar su escolarización secundaria y sus aspiraciones más globales para el futuro. En este contexto de análisis, emergieron sistemáticamente algunas ideas o nociones sobre juventud(es) y lo juvenil que están a la base de un imaginario social sobre lo juvenil como un desafio de escolarización. Algunos de dichos ejes de significación que sustentan dicho imaginario son convergentes y consistentes con algunos de los rasgos contextuales más relevantes de la sociedad chilena actual.

\subsection{Lo juvenil como proceso maduración desde la adolescencia a la juventud y al mundo adulto}

En una perspectiva dialógica con la tradición investigativa es relevante destacar que en la contingencia de la conversación social juvenil generada en torno a los grupos de discusión, resuenan algunos de los ecos de debates científicos clásicos en el campo de los estudios de juventud. Específicamente, frente a la pregunta inicial: ¿Cómo están viviendo ustedes su egreso de la Educación Secundaria?, surgen preliminarmente algunas de las siguientes respuestas:

"No alcanzas a terminar la etapa de adolescencia y ya tiene que estar preocupándose de trabajo, de estudio" (Liceo 8, Camila, L75-76).

"es un proceso, un cambio fuerte para mí, paso de ser un niño a un adulto y valerme por mí mismo" (Liceo 13, David, L38-45).

"[...] es pasar a valerse por sí mismo, no en el sentido de que ya voy a vivir sola 'altiro', [...] uno mismo se tiene que arreglar por sus propios medios" (Liceo 13, Almendra, L38-45).

"Para mi familia madurar más que nada es tomar las decisiones propias, no por lo que dice el resto y es difícil" (Liceo 13, Francisca, L87-93).

Uno de los primeros ejes que surge en el discurso de los jóvenes acerca del momento o la temporalidad biográfica que están viviendo, lo enuncian como el "paso de ser un niño a un adulto y valerme por mí mismo". En términos globales, para ellos se trata de un proceso de maduración relacionado con la toma de decisiones cruciales que permitirán configurar sus trayectorias sociales post secundarias. Desde este marco, las y los jóvenes analizan sus posibilidades de desarrollo actual o futuro, incluyendo en esta evaluación el aporte potencial que hace o potencialmente puede hacer a sus respectivos proyectos de vida la obtención de las credenciales escolares formales que acreditan ciertos conocimientos y competencias generales que desde su propia perspectiva de análisis les pueden permitir concretar algunas de sus aspiraciones de mayor autonomía personal en la configuración de sus vidas y disminuir con ello la influencia en su entorno inmediato en las decisiones más importantes en pos de concretar sus proyectos de vida.

Como se puede observar, en los fragmentos del habla social juvenil antes analizados, destaca la sistemática referencia de las y los jóvenes a la noción de transición como un proceso de maduración que iría desde un momento específico del ciclo de vida (niñez o adolescencia) a otro momento claramente diferenciado (juventud). Lo anterior, estaría marcado por cambios tanto a nivel de desarrollo biológico como psicosocial de las y los jóvenes. Se puede observar una notable convergencia del discurso de las y los jóvenes contemporáneos 
con una de las "ideas clásicas" enunciadas previamente en torno la condición juvenil a partir de las primeras décadas del siglo XX. Cabe señalar que esta significación imaginaria es transversal en los grupos de discusión.

Lo relevante de tal hallazgo es que da cuenta de la convergencia entre dos vertientes del magma socio-imaginario del cual se nutren en general los imaginarios sociales. Por una parte, los conocimientos especializados y las ideas científicas. Por otra, el habla juvenil que las re-significa cotidianamente desde su propia experiencia social. Ello permite afirmar que las significaciones imaginarias sociales (Castoriadis, 2007, p. 566) emergentes en el Chile contemporáneo encuentran un equivalente efectivo en las y los jóvenes quienes en los últimos veinticinco años han debido resolver uno de los principales enigmas sociales $o$ pruebas sociológicas que les ha impuesto la sociedad, es decir, aumentar su capacidad de agencia individual, su autonomía y su capacidad de situarse y elegir individualmente en una precaria estructura de oportunidades que se ha estructurado a partir de meritocracia y equidad social. Y en tal escenario social las mencionadas significaciones sociales, provenientes de tradiciones culturales y científicas lejanas al tiempo presente y que son representadas o puestas en circulación nuevamente por las y los jóvenes al momento de describir sus experiencias sociales respecto de la culminación del ciclo de enseñanza secundaria y como esté término o egreso de un nivel escolar marca de múltiples maneras sus trayectorias sociales futuras, incluso provocando en algunos casos unas genuinas rupturas biográficas en las y los 400 mil jóvenes que egresan cada año de este nivel educativo que en Chile.

\subsection{Lo juvenil como proceso adquisición de mayor autonomía a través de la escolarización}

Profundizando en una segunda dimensión del imaginario social de lo juvenil como desafío de escolarización en Chile, surge la idea de ampliar su autonomía personal y las capacidades de las y los jóvenes en relación a definir sus propios límites de acción tanto a nivel personal como colectivo. Tanto en la identificación de este imaginario como para la caracterización de sus significaciones más relevantes, se establece un diálogo intertextual explícito entre las nociones y conceptos surgidos a partir de un texto considerado clásico en el marco de los estudios de juventud y se pone en discusión con el contenido de los discursos juveniles contemporáneos que emergieron en la indagatoria.

Las ideas de Benedict (2008), permiten discutir en torno a uno de los hechos biográficos más importantes en la configuración del estatus juvenil y algunos de sus mecanismos socializadores involucrados en algunas sociedades históricamente determinadas. Nos referimos específicamente a la adquisición del estatus de responsable-no responsable, que sería según Benedict (2008) un proceso que guía el "paso" desde la niñez a la adultez. Particularmente, se considera relevante la observación acerca de la gradualidad e intencionalidad subjetiva, que deben incorporar procesos de socialización en el contexto de una relación de aprendizaje inter-generacional entre niños, adolescentes y adultos pertenecientes a una cultura concreta. Es decir, estos procesos de adquisición de tareas y roles adultos implican simultáneamente un proceso de subjetivación de los sujetos. Por ello, en este contexto es necesario destacar que los mecanismos de individuación constituyen una de las dimensiones inmanentes de los procesos de interiorización de ciertos valores o principios de acción colectivos. O dicho de una forma, la individuación de un sujeto constituye una de las caras o puntos de llegada de los procesos de socialización. En este sentido subjetivación y socialización constituyen la cara y el sello de un mismo mecanismo macro social clave para la reproducción del orden social (y su transformación). Por ello, la vigencia de los análisis y observaciones antes presentadas son relevantes a pesar de estar referidos a la cultura americana de mediados del siglo XX.

El texto clásico de Benedict (2008) nos permite (re)pensar las tensiones existentes en los procesos de subjetivación y constitución de sujetos juveniles en torno a las nociones de responsabilidad, autonomía, autoridad, 
disciplina, obediencia y la subordinación a los mandatos adultos. Y particularmente repensar el rol que en estos procesos estarían jugando las instituciones sociales que tradicionalmente moldeaban o cumplían dichas tareas de socialización: la familia, la escuela, entre otras instituciones.

La necesidad de analizar la eficacia institucional de las agencias tradicionales de socialización y la posibilidad de proponer mecanismos alternativos e impulsar transformaciones socio-estructurales que respondan a las nuevas demandas de mayor autonomía individual y a la par de más vida colectiva que genere las estructuras institucionales necesarias para que las y los jóvenes chilenos logren cada vez mayores espacios de autonomía personal y accedan a soportes institucionales para su ejercicio ciudadano y despliegue en su vida cotidiana. Al respecto, es relevante recordar la formulación que realizó Beck (1997) respecto de la configuración de una paradoja latente en el seno de las sociedades del riesgo: "el que quiera vivir individualmente, deberá hacerlo socialmente". Con ello se insiste en la necesidad que las sociedades contemporáneas abran nuevos caminos de integración social y configuren una red de soportes institucionales más efectivos para que los individuos y grupos que la componen junto con individualizarse, contribuyan eficazmente a la cohesión social.

En esta misma línea analítica, y como una forma de ejemplificar algunas de las significaciones emergentes en el habla juvenil, se han seleccionado alguno de los siguientes textos para graficar el modo en que dichos estudiantes tematizan sus actuales desafíos de autonomía e instituyen el imaginario social sobre lo juvenil como un desafío de escolarización:

"tengo que seguir estudiando porque si no después no voy a poder valer por mí, no voy a poder tener una familia, entonces yo tengo sustentarme primero en mí para sustentar a la gente que quiero sino no voy a poder estar así, es que necesito llegar a una meta" (Liceo 13, David,L68-73).

"todos están esperando que escoja algo y también como que están esperando algo que no sé si yo pueda cumplirlo, como que maduré de un día para otro y sepa todo lo que voy a hacer de mi vida y yo todavía no lo he pensado" (Liceo 13, Nicole, L78-84).

Las unidades de significación antes presentadas giran y convergen en torno a una segunda idea clásica de los estudios de juventud, es decir, la hipótesis que la juventud es principalmente un procesos de preparación para el mundo adulto o como un proceso de maduración y en general de lograr de mayor autonomía personal, respecto a sus pares y a su familia, lo cual incluye desde sus propios parámetros el asumir responsabilidades de modo progresivo, tanto en el tiempo presente como en el futuro. Sin embargo, en algunos de los textos analizados, dicha experiencia de egreso de la enseñanza secundaria es percibida como una ruptura intempestiva en un largo ciclo educativo que estuvo caracterizado por desplazar la carga de responsabilidad en otras agencias socializadoras: la familia, la escuela, los amigos, entre otras. Los textos anteriores aluden a procesos de subjetivación que son transversalmente percibidos por las y los jóvenes participantes, observándose en los relatos y testimonios algunos elementos discursivos que dan cuenta del distanciamiento crítico de los sujetos juveniles en torno a algunas figuras y roles adultos en torno a la autoridad, disciplina, obediencia e incluso fenómenos (in) subordinación a los mandatos adultos:

"muchas personas te presionan a que tú tienes que ser un profesional, pero muchas veces no haces lo que tú quieres, pero solamente te ponen la meta de que tú tienes que ser alguien" (Liceo 8, Camila, L55-58).

"Es más que nada la preocupación de lograr sacar un título, ser alguien, o sea $[\ldots]$ es como una preocupación de lograr las metas, cumplir esas metas y no quedar atrás, un stress [...] Cumplir la expectativa [...] Que los papás ponen, de seguir estudiando más y más y más". (Liceo 8, Diego, L36-40).

"La inversión económica, por todo los sacrificios que han hecho los demás por ti y lo que tú has hecho, por querer salir adelante y como dijo el Diego no ser 
alguien más del montón... pero es difícil, es difícil pero hay que lograrlo... de alguna forma u otra [...] En no defraudar a los que creen en uno... los sacrificios" (Liceo 8, Ian, L47-52).

Desde este punto de vista, la presencia de algunos ejes de significación simbólica que han surgido en el habla juvenil en el marco de la presente investigación y que se constituyen en elementos instituyentes (Castoriadis, 2007) del imaginario social de lo juvenil como desafío de escolarización. Los ejes emergentes son, por una parte, lo juvenil como proceso de maduración (comenzar a ser responsables, valerse por sí misma/o, preocuparse del trabajo, de los estudios, entre otras unidades de significado).Y por otra parte, lo juvenil como adquisición de mayor autonomía personal. Desde este punto de vista, la emergencia de dicho imaginario social sobre lo juvenil está muy vinculado a un conjunto de transformaciones socio estructurales que en las últimas cuatro décadas colocaron en el centro de la configuración de lo social aquellos mecanismos de mercados que se introdujeron en el ámbito de la educación, la seguridad social, y de todas la dimensiones relevantes de la vida social contemporánea en Chile. Ello, junto con naturalizar esa forma de estructurar la vida social, generó una presión en torno a los sujetos de posicionarse individualmente en dicha estructura social naturalizada. Y este esquema de producción de lo social, los procesos de escolarización y la adquisición de credenciales educativa se transformaron en el principal mecanismo de configuración de lo juvenil en un segmento significativo de las y los jóvenes chilenos contemporáneos.

Complementariamente, las transformaciones socio estructurales antes analizadas, han ido complejizando el tradicional modo de relación de los sujetos juveniles con algunos ámbitos claves de la vida social: educación, empleo y la familia, especialmente con las tensiones y conflictos en torno a los modos de ejercicio de las figuras y roles parentales y/o de autoridad. Al respecto, cabe destacar que a juicio de Araujo y Martuccelli
(2012) estos cambios estarían re-estructurando los actuales desafíos comunes o pruebas sociológicas a las que están sometidos los diversos sujetos sociales en la sociedad chilena contemporánea.

\subsection{Finalizar la enseñanza secundaria: el piso minino de la escolarización en el Chile actual}

A partir del material antes presentado proveniente de algunos grupos de discusión se da cuenta de algunas convergencias discursivas en torno a la descripción de sus "experiencias de egreso" de la enseñanza secundaria. En primer lugar, se instituye la significación imaginaria que con dicho "egreso" o finalización formal de sus estudios secundarios se cierra de una etapa mínima obligatoria de escolarización y con ello, las y los jóvenes plantean que ello es visto como un logro que satisface, aunque parcialmente en algunos casos, las expectativas de la familia en torno a la finalización de esta etapa inicial de estudios. En segundo lugar, se puede observar el énfasis de los relatos de las y los jóvenes está puesto en describir los grados de satisfacción de los padres $y$ de adultos en general que conforman su entorno social y secundariamente se refieren a la contribución social que ello hace para el logro personal de sus propias metas o cumplimientos de sus expectativas en torno al futuro. Algunos de los relatos señalan lo siguiente:

"El tema es "tienes que tener la PSU, tienes que estudiar' y siempre desde chico se te dice 'tu única misión es estudiar', pero no es la única misión que tiene una persona, no puedes encerrar a un niño por 12 años que son de estudio y si lo haces mal para él porque no desarrolla nada, una de las cosas que siempre desarrollamos acá más que el estudio, porque el estudio se hace en la casa, es desarrollo [...]que te vaya bien, que te portes bien y muchas cosas que al final son, para mí, son cosas que no tienen mucho sentido si tú no estás feliz contigo mismo, sino estás bien tú, qué sacas con tener prueba 7 , sino sabes hablar con alguien" (Liceo 13, Sebastián, L110-120). 
Como se puede observar en relación al momento del egreso de la enseñanza secundaria, este hito vinculado al tiempo biográfico es clave en el despliegue de las trayectorias juveniles post- secundarias y emerge como un momento complejo desde la experiencia social de las y los jóvenes que participaron en los diferentes grupos de discusión. Ello, en términos generales genera algunas expresiones de temor e incertidumbre tanto frente al presente como hacia futuro. No obstante, en el caso de los estudiantes de liceos que conforman el grupo de liceos donde las familias aportan menores recursos para el cofinanciamiento de la educación de sus hijos; el momento actual que implica estar ad portas del egreso no genera miedo ni presión en torno a la exigencia académica de los resultados en términos de las calificaciones finales obtenidas en el ciclo escolar que termina, ni tampoco genera una presión adicional los posibles resultados negativos en la Prueba de Selección Universitaria (PSU), dado que un mal resultado en ella, puede condicionar significativamente sus oportunidades futuras de continuar estudios superiores, pero consideran que igual pueden acceder a otras opciones de formación superior no universitarias y también al mercado laboral en diversas variantes. Es decir, las posibilidades de incorporarse al mundo del trabajo surgen como una alternativa difícil, pero plausible de abordar y cotidiana para algunos de los convocados a los grupos de discusión. En consecuencia, las expectativas sobre lo que viene no es vivida como un paso automático hacia la universidad y una cierta lejanía con los códigos de ingreso a la educación superior universitaria (PSU, puntajes, tener que elegir que estudiar y/o donde estudiar, etc.); sino más bien habría un tránsito lento y articulado entre los caminos relacionados con las posibilidades de estudiar y/o trabajar como un desafío de corto y mediano plazo. Los ejemplos citados muestran respuestas y estrategias comunes de las y los jóvenes en los cuales surgen miradas pragmáticas (sin mucha introspección) y dinámicas respectos de las oportunidades existentes en el entorno local y la lectura situacional de sus posibilidades laborales que emergen como un medio $u$ oportunidad para financiar su educación postsecundaria, su especialización y sus expectativas de inserción social postsecundarias. Por el contrario, en el caso de los estudiantes pertenecientes de liceos de mayor co-financiamiento de sus padres o aquellos pertenecientes a escuelas particulares pagadas; transversalmente en dichos casos, los temores e incertidumbre de las y los jóvenes se agudizan. Con respecto a ellos, los estudiantes los tematizan como "presión académica" e incertidumbre acerca de su futuro post egreso de la escuela secundaria y sobre todo surge el temor a defraudar las expectativas de los padres, a ser menos que los padres y no poder lograr sus metas personales y familiares.

\subsection{Expectativas y aspiraciones de los jóvenes chilenos contemporáneos: continuar estudiando, trabajar y auto-realización personal}

Desde otro ángulo de análisis, la conversación social sobre el desafío o necesidad de continuar estudiando en la educación superior, en cualquiera de sus ofertas posibles, se articulan en torno a un eje de significado donde la profesionalización, la especialización y los estudios terciarios es instituida imaginariamente como una alternativa viable de lograr determinados niveles de calidad de vida y consistente con sus finalidades. Algunas de las formulaciones realizadas por los estudiantes son las siguientes: estabilidad económica, una buena calidad de vida, tendremos una buena vida, vivir tranquilos, vivir cómodos, vivir con holgura, vivir sin deudas, no endeudarse, entre otros elementos de sentido que emergen entre las y los jóvenes chilenos que egresan de la educación secundaria en el Chile contemporáneo. A modo de ejemplo, se presentan los siguientes textos:

"Yo aspiro a vivir cómoda, a no sé ir los fines de semana a comer algo rico, no cocinarme yo, después llegar llevar a los niños no sé a un cumpleaños, porque yo quiero tener familia y quiero tener una buenas vacaciones quizá en otro país, vivir súper cómoda, no vivir así como clase media donde yo nací po', nací en clase media pero quiero siempre es uno como que vela por más, más, más 
entonces si estoy acá en clase media quiero obviamente no sé ABC1" (Liceo 13, Almendra, L344-349).

“QQué viene para adelante?, yo creo que para mí es estudiar, estudiar es como lo más importante, todavía no estoy bien enfocado en algo en especial, pero después de aquí, no trabajar [...] y eso po que me gustaría estudiar nomas y sacar una carrera profesional, y lo que es importante es que después del Cuarto Medio no salir a trabajar, eso es lo que me interesa, querer hacer algo bueno" (Liceo 10, Franco, L41-48).

"Aparte de la estabilidad económica y una buena calidad de vida, después que nosotros estudiemos y todo eso, tendremos una buena, vivir tranquilos, sin deudas, si uno quiere algo se lo puede comprar, pero no endeudarse y todo eso, porque igual yo por lo que he visto, mi familia igual muchas deudas y todo eso, y a mí no me gustaría tener eso, es como vivir amarrado" (Liceo 10, Nicolás, L235-239).

Se puede observar que las expectativas y las aspiraciones de los y las jóvenes oscilan entre estudiar o trabajar como una forma de responder subjetivamente al desafío personal y la presión familiar emergente en el Chile actual por obtener estudios terciarios y a la vez incorporarse en mejores condiciones al mundo adulto y a la vida del trabajo. Estos últimos desafíos funcionales relativos a la integración social o sistémico han sido descritos por algunos investigadores como un "desafío sociológico"1 (Martuccelli \& de Singly, 2012) emergente en el Chile contemporáneo y que describe una condición juvenil transversal que enfrentarían las y los jóvenes participantes de los grupos de discusión de los liceos municipales y aquellos particulares subvencionados de bajo cofinanciamiento familiar y que subjetivamente

1 Es una noción teórica que busca articular los problemas personales con las estructuras sociales que los crean o amplifican. $\mathrm{Su}$ objetivo es lograr caracterizar precisamente los desafíos a los que son sometidos los actores y las maneras en que los individuos superan, o intentan superar las pruebas. La noción permite articular lo individual y lo colectivo en la explicación (imaginación) sociológica (Martuccelli \& de Singly, 2012, p. 72). se manifiesta en una doble presión a los actores escolares que "egresan" del sistema escolar secundario. Como se señaló anteriormente, el primero desafío relevante en la temporalidad biográfica juvenil es lograr egresar de cuarto medio o de la secundaria con los mejores resultados posibles (expectativas) y luego, la consiguiente presión de seguir estudiando en educación superior (en cualquiera de sus posibilidades que otorga el sistema terciario en Chile). Lo anterior, surge casi como una nueva obligatoriedad social de las juventudes chilenas contemporáneas. Es el desafío y la demanda de la escolarización como principal estrategia que permite una suerte de acumulación originaria de capital cultural o más precisamente con algunas credenciales escolares que le permitan posicionarse estratégicamente en la estructura de clases de la sociedad chilena contemporánea.

En el caso de los liceos de Talca, Punta Arenas y de otras regiones del país; el discurso juvenil sobre el desafío de continuar estudiando se articula simultáneamente con la necesidad de trabajar para pagarte tu carrera universitaria o ayudar a tus padres a pagar la Universidad, entre otros significados emergentes en este contexto escolar y familiar con marcadas connotaciones regionales. De este modo, el seguir estudiando, estudiar y trabajar, me voy a meter en un preuniversitario y trabajar; configuran algunas de las estrategias que despliegan las y los jóvenes chilenos en el contexto de un escenario económico, social, político y cultural que en las últimas dos décadas había consolidadouna visión naturalizada de un tipo de sociedad estructurada en base a los mecanismos de mercado, tanto para el acceso a ciertos a bienes de consumo como para el acceso a los bienes públicos como educación, salud, seguridad social, vivienda, entre otros. Por lo tanto, en tal escenario fue donde se impuso y naturalizo una lógica económica como principio estructurante de la vida social contemporánea y la escolarización en todas sus formas, se convirtió en el principal dispositivo instituyente de un imaginario social de lo juvenil que colocó el desafío de la escolarización como la principal herramienta que permitía resolver el enigma o la prueba sociológica más importante para acceder al desarrollo humano a partir del despliegue de las 
capacidades de agencia individual y colectiva de las y los jóvenes chilenos en el escenario social de post-dictadura en Chile (1990-2015).

De tal modo el imaginario social de lo juvenil desafío de escolarización se ha consolidado en la historia económica, social, política y cultural de las juventudes chilenas contemporáneas y muestra todo su predominio a partir de la segunda década del Siglo XXI en Chile. Al respecto un dato que ejemplifica esta hegemonía cultural es que las y los jóvenes chilenos que comienzos del año 1990 accedían a la educación superior eran alrededor de 200 mil personas y 25 años después esa cifra creció a un millón trescientas mil jóvenes que se encuentran en la actualidad en alguna institución de educación superior chilena.

\section{Conclusiones}

Entre los resultados más relevantes de esta investigación destaca la re-afirmación que la emergencia de las juventud(es) y de lo juvenil en el mundo contemporáneo, es un proceso de construcción social complejo y conflictivo, que integra diversas dimensiones y remite figuras e imágenes sociales en permanente tensión o conflicto, en pos de estructurar miradas hegemónicas que sean funcionales a determinados modelos de desarrollo, tanto en Latinoamérica como en Chile en las últimas cinco décadas.

El estudio permitió identificar una configuración socio-imaginaria claramente diferenciado y hegemónica en el seno de la sociedad chilena contemporánea. Un imaginario social sobre lo juvenil como un desafío de escolarización permanente. Alternativamente, se plantea a modo de hipótesis para futuras investigaciones la emergencia de un imaginario social sobre lo juvenil como proceso de politización que emerge de las actuales tensiones y conflictos de diversos actores sociales en pos de concretar profundas transformaciones socio estructural de la sociedad chilena post dictadura. Ambos imaginarios se estructurarían conflictivamente sobre la base de enfatizar diversas dimensiones y procesos considerados claves en la configuración de la condición social de las juventudes chilenas contemporáneas.
En relación al imaginario social sobre lo juvenil como un desafío de escolarización, éste ha logrado la hegemonía cultural en los últimos veinticinco años, desde el inicio del proceso de transición a la democracia en 1990 y cuya vigencia se mantiene hasta la actualidad. Sin embargo, y a modo de hipótesis teórica, se sostiene que dicho imaginario ya comienza a mostrar sus debilidades estructurales y a ser re-significado por los propios sujetos en el marco de un nuevo escenario social estructurado en la sociedad chilena actual. Lo anterior, ha sido destacado en análisis recientes por diversos autores (Aguilera \& Muñoz, 2015). Al respecto, se sostiene lo siguiente: "Al mismo tiempo, así como diversas definiciones, deslindes e imágenes asociadas a la juventud conforman conceptos estructurados socialmente y orientados a incidir en la disputa por la producción de sociedad, continuamente emergen definiciones sobre ámbitos de la política, lo social y los movimientos sociales que tienen su origen en proyectos e intereses enfrentados en las conflictividades políticas" (Aguilera \& Muñoz, 2015, p. 70). La relevancia y pertinencia del texto citado, radica en mostrar clara y sugerentemente que así como no existe "lo juvenil" como una categoría teórica homogénea y menos que pueda ser definida a partir de unos contenidos universales y vigentes en cualquier tiempo o espacio social; tampoco lo es la noción de política o lo político y sus múltiples conexiones con la sociedad que le da origen y de la cual toma sus rasgos sociohistóricos más característicos.

En este marco de configuración de un nuevo escenario político y social en la sociedad chilena del último lustro, es posible sostener prospectivamente una eventual emergencia y despliegue de nuevos imaginarios sociales sobre lo juvenil. Uno de estos imaginarios que puede ir cobrando fuerza y una nueva vigencia, es una construcción socio imaginaria de lo juvenil concebido como proceso de politización, protagonismo y rebeldía juvenil que tiene amplias posibilidades de consolidarse como una respuesta contra cultural al imaginario dominante de lo juvenil como desafío de escolarización. Ello, considerando, que tal como lo señala el último informe de 
desarrollo humano en Chile: "las señales de la politización son diversas [...] no se limitan a un único espacio de la sociedad, sino que se expresa en diversos planos de lo social: como ampliación de la discusión pública, como aumento de la conflictividad y la movilización social, como involucramiento ciudadano" Chile (Pnud, 2015, p. 15). Consistentemente con lo anterior, en diversos espacios y ámbitos de la vida social actual se observa una demanda y protagonismo de diversos actores sociales en la toma de decisiones, donde las y jóvenes se despliegan cada vez con mayor visibilidad.

Finalmente, entre las limitantes de los resultados presentados, se encuentra la opción metodológica que guió la presente investigación y que dice relación con investigar sólo el habla social de las y los jóvenes chilenos escolarizados. Ello, por considerar que este segmento de las juventudes constituye una de las mejores metáforas de las transformaciones socio-estructurales que se han cursado en la sociedad chilena en las últimas cuatro décadas. No obstante lo anterior, se reconoce la necesidad de incorporar en el futuro trabajo de campo de esta investigación a jóvenes con otras trayectorias sociales, no escolarizadas, segmentos juveniles que hayan formado ya sus propias familias y sobre todo jóvenes que se encuentren insertos en el ámbito productivolaboral o excluidos de dichos mercados de trabajo, entre otras múltiples posiciones sociales que ocupen jóvenes chilenos contemporáneos.

\section{Lista de referencias}

Acosta, Y. (2011). La constitución del sujeto en la filosofía Latinoamericana. En E. Gruner. (coord.) Nuestra América y el pensar crítico. Fragmentos de Pensamiento Crítico de Latinoamérica y el Caribe, (pp.75-90). Buenos Aires: Consejo Latinoamericano de Ciencias Sociales.

Aguilera, O. \& Muñoz, V. (2015). Preguntas por la juventud, preguntas por la política. Acción colectiva, movimientos sociales y militancia en los estudios de juventud. Chile 1967-2013. En P. Cottet (ed.) Juventudes: Metáforas del Chile contemporáneo, (pp. 69-103). Santiago de Chile: RIL.
Alpízar,L.\& Bernal, M.(2003). La Construcción Social de las Juventudes. Última Década, 11 (19), pp. 105-123. Doi: https://dx.doi. org/10.4067/S0718-22362003000200008.

Araujo, K. \& Martucelli, D. (2012). Desafios comunes. Retrato de la sociedad chilena y sus individuos. Tomo I. Neoliberalismo, democratización y lazo social. Santiago de Chile: LOM.

Baeza, M. A. (2003). Imaginarios sociales. Apuntes para la discusión teórica y metodológica. Concepción: Universidad de Concepción.

Beck, U. (1997). Kinder der freiheit. Frankfurt: Suhrkamp.

Benedict, R. (2008). Continuidades y discontinuidades en el condicionamiento cultural. En J. A. Pérez-Islas (comp.) Teorías sobre la juventud. Las miradas de los clásicos, (pp.35-45). México, D. F.: Unam.

Canales, M. (1994). El estudio de la realidad social con metodologías cualitativas. Santiago de Chile: Ministerio Secretaría General de Gobierno, División de Organizaciones Sociales.

Canales, M., Ghiardo, F. \& Opazo, A. (2015). Para un concepto de juventud. En P. Cottet (ed.) Juventudes: Metáforas del Chile contemporáneo, (pp. 47-67). Santiago de Chile: RIL.

Castoriadis, C. (2007) La institución imaginaria de la sociedad. Buenos Aires: Tusquets.

Dávila, O. (2015). Juventud y trabajo: Entre tránsitos y trayectos. En P. Cottet (ed.) Juventudes: Metáforas del Chile contemporáneo, (pp. 143-159). Santiago de Chile: RIL.

Duarte, C. (2015). Estudios juveniles en Chile: Devenir de una traslación. En P. Cottet (ed.) Juventudes: Metáforas del Chile contemporáneo, (pp. 23-45). Santiago de Chile: RIL.

González, Y. \& Feixa, C. (2013). La construcción histórica de la juventud en América Latina. Bohemios, Rockanroleros $\&$ Revolucionarios. Santiago Chile: Cuarto Propio.

Hinkelammert, F. (2003). El sujeto y la ley. El 
retorno del sujeto reprimido. San José: Euna.

Hurtado, D. (2004). Globalización y Exclusión: De la invisibilización a la visibilización consumista de los jóvenes y los imaginarios de resistencia. Última Década, 12 (20), pp. 107-120. Doi: https://dx.doi.org/10.4067/ S0718-22362004000100006.

Martuccelli, D. \& Singly, F. (2012). Las sociologías del individuo. Santiago de Chile: LOM.

Mattelart, A. \& Mattelart, M. (1970). La juventud chilena: Rebeldía y conformismo. Santiago de Chile: Universitaria.

Pérez-Islas, J. A., Valdez-González, M. \& Suárez, M. (2008). Teorías sobre la juventud. Las miradas de los clásicos. México, D. F.: Unam.

Pintos, J. L. (2014). Algunas precisiones sobre el concepto de imaginarios sociales. Revista Latina de Sociología, 4, pp. 1-11. Recuperado de: http: // revistalatinadesociologia.com, ISSN 2253- 6469.

Pnud (2015). Desarrollo Humano en Chile. Los tiempos de la politización. Santiago de Chile: Programa de la Naciones Unidas para el Desarrollo.

Zemelman, H. (1998). Sujeto existencia y potencia. México, D. F.: Anthropos. 